\title{
ASPECTOS PARODÍSTICOS EM O DIA DOS PRODÍGIOS.
}

\author{
Elisangela Fátima Nogueira Godêncio ${ }^{1}$
}

\section{Resumo}

Este artigo focaliza os aspectos parodísticos encontrados em O Dia dos Prodígios, de Lídia Jorge. Essa análise parte, inicialmente, de um referencial teórico abordando alguns conceitos estudados por pesquisadores conhecidos no mundo da Linguística, por exemplo: Mikhail Bakhtin, Leonor Fávero, Afonso Sant'anna e Diana Luz Barros. Através das obras desses autores propõe-se analisar, observando as ações das personagens, como se processa o efeito paródico neste romance.

Palavras-chave: Paródia; Dialogismo; Linguagem; Literatura.

\begin{abstract}
This article focuses on some parody aspects found in The prodigies' day, written by Lidia Jorge. The analysis departs from a theoretical approach based on some concepts studied by well-known researchers in the world of Linguistics, such as Mikhail Bakhtin, Leonor Fávero, Afonso Sant'anna and Diana Luz Barros. Through those authors' works, this article intends to analyze, by observing the actions of the characters, how to process the parody effect in this novel.
\end{abstract}

Keywords: Parody; Dialogism; Language; Literature.

Inserida no contexto cultural português inaugurado após a Revolução dos Cravos (abril de 1974), Lídia Jorge publica seu primeiro romance O Dia dos Prodígios na década de 80. O romance destaca uma comunidade que vive em uma aldeia fictícia, Vilamaninhos, e neste ambiente encontram-se pessoas que acreditam em histórias mirabolantes, criadas pelos próprios moradores. Essas criações provêem da falta de ocupação daqueles que ali habitam e, principalmente, por viverem em um vilarejo em condições atrasadas (em relação a outras cidades portuguesas). Seca e estéril, a cidade vê morrer o rio, fugir o padre, o que resulta no fechamento da comunidade em si

\footnotetext{
${ }_{1}$ Professora de Literatura da Faculdade Eça de Queirós; Mestre em Literatura Portuguesa pela Universidade de São Paulo; Doutoranda em Literatura Portuguesa pela Universidade de São Paulo.
} 
mesma. E isso, ao invés de estreitar as relações sociais entre o povo do vilarejo, ao contrário, estimula confronto e dá ensejo à solidão.

Ao construir esta narrativa, a autora contempla uma gama variada de temas se valendo de elementos que apontam para o culto ao passado; para a submissão da mulher perante o homem e para a opressão. Há, ainda, a presença da Revolução dos Cravos, fato histórico que dá sustentação à narrativa.

No âmbito da linguagem, um recurso significativo de que a autora se vale é a paródia, que se mostra por meio das ações de algumas personagens e pelo efeito parodístico que se forma em torno destas ações.

A paródia aponta para duas posições principais: tanto para a riqueza simbólica de que se reveste um discurso, por um lado, quanto para conduzir a decodificações que levam ao que se pode chamar de "avesso do texto", por outro. Há, portanto, "uma nova e diferente maneira de ler o convencional; um processo de liberação do discurso e uma tomada de consciência crítica" (SANT'ANNA, 2000, p. 31). Considera-se a paródia, então, um ato crítico de reavaliação e acomodação, pois recusa e esvazia um modelo original para recriar e preencher um modelo preexistente.

Como postulou Sant'anna (2000), a paródia apresenta-se como canto paralelo, como diálogo intertextual ou como simples retomada de um texto preexistente que se afirma ao se negar. Considerada como a linguagem da inversão, a paródia inscreve o "mesmo", mas obliquamente, ao revés, revirado, e o reconduz ao novo texto como crítica. Como linguagem de ruptura, este recurso procura um corte com o convencional realizando uma inversão e um deslocamento. Em outras palavras, a paródia apresenta-se como uma escrita autocrítica, a voz social ou individual reprimida, que é preciso desentranhar para que se conheça o outro lado da "verdade".

Isso posto, pode-se afirmar que Bakhtin, a partir do formalismo russo, é o primeiro teórico a apresentar o conceito de dialogismo a partir da redefinição de outros conceitos anteriores a este, a paródia e a estilização. O conceito de paródia torna-se mais sofisticado a partir de Tynianov, quando é feito um estudo lado a lado com o conceito de estilização. Verifica-se, porém, que há uma coincidência com relação aos pensamentos destes teóricos. Tynianov, citado por Sant'anna defendeu que 
Mas na paródia, os dois planos devem ser necessariamente discordantes, deslocados. (SANT'ANNA, 2000, p. 13)

Já na estilização não há discordância e sim concordância nos dois planos. Portanto, da estilização à paródia não há mais que um passo, pois quando a estilização se mostra como uma motivação cômica acaba se convertendo em paródia.

Sob a ótica de Bakhtin, apesar das diferenças substanciais, a paródia pode ser colocada ao lado da estilização, pois, de acordo com Fávero (1999, p. 53) ambas apresentam traços em comum, que "permitem reconhecer explicitamente uma semelhança com aquilo que negam”. Desse modo, a palavra se apresenta com um duplo sentido, voltando-se para o discurso de um outro e para o objeto do discurso como palavra. Por outras palavras, em um único discurso podem-se encontrar duas orientações interpretativas, ou seja, duas vozes. Sendo assim, na paródia a linguagem torna-se dupla, pois se mostra como uma escrita transgressora, que engole e transforma o texto primeiro, reestruturando-se sobre ele, mas, ao mesmo tempo, negando-o.

O princípio dialógico permeia a concepção de Bakhtin de linguagem, e, quem sabe, de mundo e de vida. Dialogismo é o princípio constitutivo da linguagem, e este, em qualquer campo e em qualquer circunstância, está impregnado de relações dialógicas. A concepção dialógica contém a ideia de relatividade da autoria individual e, consequentemente, o destaque do seu caráter coletivo. Nesta concepção, o homem não se constitui isoladamente e a experiência de vida deste indivíduo se tece na relação com o outro.

Pensar em relação dialógica é remeter a outro princípio - a não autonomia do discurso. Para tanto, na linguagem bakhtiniana, a noção do eu nunca é individual, mas social. Os processos de formação do eu, para Bakhtin, se desenvolvem por meio de três categorias: o eu-para-mim, o eu-para-os-outros, o outro-para-mim. Sendo assim, a concepção de diálogo somente se concretiza na relação subjetiva "eu-tu". Para o autor, o dialogismo interacional só pode ser entendido pelo deslocamento do conceito de sujeito. O sujeito perde o papel de centro para ser substituído por diferentes, ainda que duas, vozes sociais. Deste modo,

concebe-se o dialogismo como espaço interacional entre o eu e o tu ou entre o eu e o outro, no texto. Explicam-se as freqüentes referências que faz Bakhtin ao papel do 'outro' na constituição do sentido ou sua 
insistência em afirmar que nenhuma palavra é nossa, mas traz em si a perspectiva de outra voz (BARROS, 1999, p. 3).

No dialogismo há, ainda, outro aspecto a ser observado: aquele que se refere ao diálogo entre os muitos textos da cultura, a intertextualidade. Deve-se notar que a intertextualidade, segundo Bakhtin, se processa, primeiramente, no interior do texto, mostrando-se como uma intertextualidade interna, que se apropria de vozes que falam e polemizam no texto. Deste modo é a partir deste vozear que se produz o diálogo com outros textos.

Em O Dia dos Prodígios, a autora constrói o texto de modo a estabelecer um diálogo também com outros textos. Dessa maneira, o efeito paródico pode ser notado quando faz referência aos ilustres heróis portugueses - Viriato, Egas Moniz, Vasco da Gama, Luso, dentre outros - que, nos feitos portugueses, revelam-se

Bravos em vista e feros nos aspeitos, / Mais bravos e mais feros se conhecem, / Pela fama, nas obras e nos feitos; / Antigos são, mas inda resplandecem / Co'o nome entre os engenhos mais perfeitos (CAMÕES, s/d, p. 283).

Todas essas figuras que comparecem na obra de Camões estão representadas na obra de Lídia Jorge pelas personagens Manuel Gertrudes, Macário, Pássaro Volante, José Jorge Júnior, mas estes não são garbosos e dotados de coragem como os primeiros, são frágeis. Por meio desta intertextualidade observa-se a construção de um mundo ao contrário, não somente pela caracterização dos heróis, mas também pelo comportamento dos habitantes do vilarejo. E este mundo ao contrário remete à paródia.

Há, na obra em questão, outro episódio que mostra a personagem Carminha Rosa, encontrando (exatamente quando está no banheiro fazendo suas necessidades) uma foto minúscula estampada em um pequeno recorte de jornal. Neste "rectangulozinho junto a margem onde começavam os discursos" (JORGE, 1982, p. 98) estava anunciada a morte do noivo de Carminha Parda, sua filha. Carminha, a Rosa, não acredita no que lê, então "pôs-se a ler alto para ter a certeza de que era mentira o que acabava de compreender. Mas quanto mais e mais alto lia, mais lia a mesma coisa" (JORGE, 1982, p. 98). Existe, neste fragmento, um confronto entre dois mundos: o da cultura e o da natureza (entendendo-se por mundo da natureza aquele que os indivíduos não ascendem a um grau mais elevado de consciência porque não tiveram acesso à educação). 
Esse episódio permite constatar a precariedade das condições intelectuais daqueles moradores e o pouco acesso à educação e aos meios de instrução. A voz narrativa capta, solidariamente, a dificuldade da personagem em captar o sentido daquelas palavras, dificuldade a que se somam o desespero e a ansiedade, conforme fica implícito no enunciado a seguir:

E Carminha Rosa, com o dedo indicador apontado, e os olhos convergindo nas letras, pôde exercitar a vista. Leu palavras e palavras. Depois palavras com palavras. E depois pensou nos pensamentos das palavras dos quadradinhos (JORGE, 1982, p. 98).

O trecho em que a mãe toma conhecimento da morte do noivo da filha é muito significativo. Ele ganha dramaticidade pelo modo como ocorre a situação e como a cena é narrada: a personagem Carminha Rosa está em um momento que poderia ser considerado de total privacidade, mas não o é, pois a latrina está construída a céu aberto, tendo ao alcance das mãos um pedaço de papel jornal que, além do rádio, ou 'telefonia' de Pássaro Volante (uma das personagens mais idosas da narrativa) era o único meio de comunicação que se tinha entre a vila e o mundo.

A esse respeito, nota-se que há um rebaixamento da privacidade, pois aquele era um momento muito particular e impróprio para a descoberta da morte de alguém de seu convívio e, particularmente, de um soldado que ela considerava como um herói da pátria. Mas não somente a perda da privacidade é evidenciada. Além disso, existe a presença do escatológico, pois, pelo que parece, nada mais importa, já que qualquer ação que se desenvolva na Vilamaninhos está caminhando para o fim do homem e do mundo. Sendo assim, as ações se desenrolam sem que se discrimine o público do privado e pouca importância se dá às coisas e às pessoas.

Observa-se a demonstração da importância que se dava a um "herói da pátria", pois aquele morreu num ato de bravura, defendendo sua pátria, e sua morte foi descoberta por acaso. A notícia veio em meio à propaganda de produtos, como se o herói fosse mais um produto descartável. Isto ressalta a condição rebaixada e marginalizada a que a autora nivela o reconhecimento que os veículos institucionais conferem aos defensores da pátria. Este é um modo de representação do herói de maneira paródica, pois, como mostra a obra de Lídia, ele não recebe o devido glamour que merece, não sendo exaltado e enaltecido a ponto de ter sua morte anunciada em um 
jornal em meio a outras notícias sem a menor importância. Desse modo, o herói, na obra em questão, apresenta-se de maneira contrária à convencional, pois se insere em um "mundo às avessas", como descreveu Bakhtin em seu estudo sobre Rabelais. Enfim, a defesa da pátria acaba sendo reduzida a uma "caganificância".

Outro episódio que contém um efeito paródico é aquele que se refere aos cães copulando em praça pública. Apresenta-se, então, a descrição desse ato sexual entre os animais no seguinte trecho:

O cão amarelo-trigo tinha possuído a cadela no meio do largo, e sendo a cadela um palmo de mão mais baixa do que o seu macho, ficava ela com as patas traseiras penduradas, Virando a cabeça para um e outro lado. Os olhos líquidos pranteados, $\mathrm{E}$ os outros, amansados, observavam deitados e em pé, de orelha em riste, complacentes e espectadores (JORGE, 1982, p. 120).

Interessante observar que os vilamaninhenses param para ver o espetáculo que acontece na praça. Para eles aquilo era algo extraordinário e, por isso, tamanha importância era dada ao fato. Isto ocorre porque não acontece nada de diferente no vilarejo e, além disso, evidencia quão rudimentar é o nível e consciência daquela gente. Sendo assim, usando a fundamentação de Bakhtin (2002), o espaço de Vilamaninhos é o do segundo mundo, da segunda vida, que existe paralelamente ao mundo oficial, o da realidade lisboeta.

Esta maneira de ver o mundo está vinculada ao que o pensador russo chamou de “paródia carnavalesca". Ela se caracteriza pela lógica original das coisas "ao avesso" e pelas permutações constantes do alto e do baixo, dando uma idéia de degradação do alto "sublime" para se aproximar do baixo "grotesco". Um traço marcante do "realismo grotesco" é o "rebaixamento", isto é, a transferência ao plano material e corporal, de tudo aquilo que é elevado. De acordo com Bakhtin (2002, p. 18), a degradação do sublime parece não apresentar um caráter formal, pois “o ‘alto' e o 'baixo' possuem um sentido absoluto e rigorosamente topográfico. O 'alto' é o céu, o 'baixo' é a terra”.

Na obra em estudo, nota-se o 'baixo' quando se toma como exemplo o episódio dos cães. Trata-se de uma cena que começa em uma taberna, no momento em que o Sargento Marinho, o segundo noivo de Carminha Parda, narra suas aventuras em África. Era tarde de domingo e todos estavam ali em volta da praça: uns assistindo à missa que acontecia; outros na taberna ouvindo as histórias do Sargento; enquanto outros 
passeavam pela praça. Em meio a estes acontecimentos surgem na praça alguns cães, cheirando-se e revolvendo-se as caudas umas atrás das outras. De repente,

O cão amarelo-trigo, tinha possuído a cadela no meio do largo, e sendo a cadela um palmo de mão mais baixa do que o seu macho, ficava ela com as patas traseiras penduradas, Virando a cabeça para um e outro lado. Os olhos líquidos pranteados. E os outros, amansados, observavam deitados e em pé, de orelha em riste, complacentes e espectadores (JORGE, 1982, p. 120).

Diante desta situação, surge um constrangimento e isto causa certo incomodo naqueles que presenciam o fato. Por isso, o Sargento "brandiu o cajado entre os dois corpos" (JORGE, 1982, p. 122) e decepou o órgão genital do cão.

Por meio do comportamento desumano do Sargento Marinho em relação aos cães é possível observar que há algo diferente no que se refere aos papéis sociais, pois o homem (aquele que se pretende racional e dotado de consciência) age claramente como um animal, pela ação que se desencadeia no episódio dos cães. O Sargento, aquele que se posiciona como dominador, heróico, pelos atos de bravura que coloca em evidência quando relata suas aventuras em África, rebaixa-se ao nível dos animais quando castra o cão. Ao rebaixar o sargento também se rebaixa os heróis portugueses, pois, pelo que se nota, ele representa aqueles que lutaram bravamente pela pátria. Este rebaixamento sugere um nivelamento, pois o oficial, por meio de suas atitudes, deixa vir à tona o seu instinto animal e este se sobrepõe à racionalidade que caracterizaria os humanos.

Vale a pena ressaltar que o rebaixamento não carrega em si somente o aspecto negativo, pois a degradação cava o túmulo corporal para dar lugar a um novo nascimento. Desse modo, a atitude do Sargento, na realidade, serviu para tirar Carminha Parda da condição de sonhadora, pois, ao presenciar aquela cena de castração literal, ela adverte: "quando chegar em casa, vou poder dizer. À minha mãe desconsertada. Solte as galinhas, embrulhe os lençóis, ponha uma guita, faça um laço, guarde as louças. Que eu vou dizer que não" (JORGE, 1982, p. 124). A partir do momento em que Carminha decide não se casar, ela renasce, e se abre, diante dela, uma janela para o mundo, para a vida. Por esse motivo, atribuí-se ao rebaixamento, não somente um valor destrutivo, mas, também, um valor regenerador. Segundo Bakhtin, o realismo grotesco não conhece outro baixo (o baixo é a terra que dá vida, é sempre o começo). 
O mesmo episódio dos cães permite observar a relação entre o raciocínio político (quando o Sargento enaltece o heroísmo português) e o mítico (no que se refere à Carminha). Logo depois da castração, quando Carminha opta por não casar, parece que ela está sendo chamada para a realidade. Ela deixa de olhar para um passado remoto, para um tempo mítico, resolve assumir o presente e se coloca à disposição para o que está por vir. Neste momento, Carminha não está mais preocupada se vai ou não encontrar um noivo; o importante é que ela abandonou aquela condição de mulher isolada e passou a esperar por algo, independentemente do que pudesse acontecer. Neste caso, parece que, involuntariamente, o Sargento, com seu ato grotesco, propiciou, para Carminha, o despertar de uma visão de mundo que se amplia e se estende para além do microcosmo de Vilamaninhos.

As imagens grotescas conservam uma natureza original e estas são diferentes das imagens da vida cotidiana, preestabelecidas e, aparentemente, perfeitas. São imagens que parecem disformes, monstruosas e horrendas, mas se inserem na vida real e se opõem às imagens clássicas do corpo humano acabado e perfeito. Como se criassem, em praça pública, com este episódio, um tipo particular de comunicação, inconcebível em situações normais. Desse modo, formas especiais de vocabulário são elaboradas: francas, sem restrições e liberadas das normas correntes de etiqueta e de decência.

Exemplifica-se este fato por meio de um relato feito pela personagem Manuel Gertrudes, que conta ao Sargento um caso de uma moça que foi estuprada pelo avô: "O filho da puta do velho. Tão velho que parecia um insecto [...] Serviu-se da moça sua neta que apenas tinha treze anos..." (JORGE, 1982, p. 120). Há, neste discurso, a falta de polidez e o uso de expressões inconvenientes. Este tipo de linguagem aproxima as pessoas do vilarejo dando um tom de linguagem familiar, pois se caracteriza pelo uso frequente de grosserias, ou seja, de expressões e palavras injuriosas. Este modo discursivo se evidencia não somente neste trecho, mas ao longo de todo o romance, principalmente quando a personagem Jesuína Palha se manifesta.

Há também, na narrativa, momentos em que se faz referência a insetos convivendo com as personagens, formigas, por exemplo. Este inseto era uma praga que havia se instalado na casa das personagens José Jorge Junior e Esperancinha Tereza (casal de idosos que habitam a vila) e "quando marido e mulher se sentaram à mesa. Já as encontraram no pão e nos copos, banqueteando-se muito antes dos donos da casa" 
(JORGE, 1982, p. 132). Trata-se de pequenos insetos que tomam toda a atenção de José Jorge, pois estendia "toda a palma da mão, à direita, muito mais hábil em tais circunstâncias, e curvado para os ladrilhos da casa, procurava durante horas carrilhos de formigas" (JORGE, 1982, p. 132). O comportamento de José Jorge pode ser um exemplo de ensimesmamento, pois, enquanto se preocupa com as formigas, soldados e grandes chefes fazem uma revolução (no caso a dos Cravos). Isto mostra que não somente José Jorge, mas toda a comunidade de Vilamaninhos parece não ter consciência do que estava acontecendo ao redor. Eles se igualam a insetos (quando José Junior, ao curvar-se para procurar as formigas, rebaixa-se para ficar no mesmo nível que elas) e a animais (no que se refere aos cães). Esta condição inferiorizada e rebaixada na qual se colocam não permite que grande parte dos vilamaninhenses evoluam intelectualmente.

Pelo que se pode notar, o recurso à paródia carnavalesca está presente em quase toda a narrativa, assinalando a distância irremediável entre os dois universos: o da civilização e o da sociedade periférica da aldeia.

\section{BIBLIOGRAFIA}

BAKHTIN, Mikhail. A Cultura Popular na Idade Média e no Renascimento: o contexto de François Rebelais. Trad. Yara Frateschi Vieira. 5. Ed. São Paulo: Editora Hucitec, 2002. . Marxismo e Filosofia da Linguagem. Trad. Michel Lahud e Yara Frateschi Vieira. 11. Ed. São Paulo: Editora Hucitec, 2004. BARROS, Diana Luz Pessoa de. Dialogismo, Polifonia e Enunciação. In: BARROS, Diana Luz Pessoa de; FIORIN, José Luiz. (Orgs.). Dialogismo, Polifonia, Intertextualidade: Em torno de Bakhtin. São Paulo: Editora da Universidade de São Paulo, 1999.

CAMÕES, Luís de. Os Lusíadas. São Paulo: Círculo do Livro, s.d. . Os Lusíadas (episódios). Apresentação e Notas: Ivan Teixeira. São Paulo: Ateliê Editorial, 2001

CASSIRER, Ernst. Linguagem e Mito. Trad. J. Guinsburg e Miriam Schnaiderman. São Paulo: Perspectiva, 1972. 
CLARK, Katerina e HOLQUIST, Michael. Mikhail Bakhtin. Trad. de J. Guinsburg. São Paulo: Perspectiva, 1998.

FÁVERO, Leonor Lopes. Paródia e Dialogismo. In: BARROS, Diana Luz Pessoa de; FIORIN, José Luiz (Orgs.) Dialogismo, Polifonia, Intertextualidade: Em torno de Bakhtin. São Paulo: Editora da Universidade de São Paulo, 1999.

GOMES, Álvaro Cardoso. A voz itinerante: ensaio sobre o Romance Português Contemporâneo. São Paulo: Editora da Universidade de São Paulo, 1993.

HUTCHEON, Linda. Poética do pós-modernismo: história, teoria, ficção. Trad. Ricardo Cruz. Rio de Janeiro: Imago Ed., 1991. . Uma teoria da paródia. Trad. Teresa Louro Pérez. Rio de Janeiro: Edições 70, 1985.

JORGE, Lídia. O Dia dos Prodígios. 3. Ed. Lisboa: Publicações Europa-América, 1982. SANT'ANNA, Affonso Romano de. Paródia, Paráfrase \& Cia. São Paulo: Editora Ática, 2000. 